\title{
Computer Vision Syndrome: Will the Pandemic Lead to Eye Problems for Dentists?
}

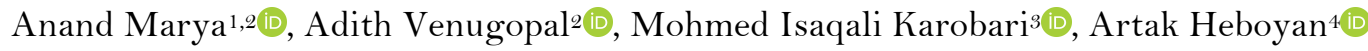

\begin{abstract}
'Department of Orthodontics, Faculty of Dentistry, University of Puthisastra, Phnom Penh, Cambodia.
${ }^{2}$ Center for Transdisciplinary Research, Saveetha Dental College, Saveetha Institute of Medical and Technical Science, Saveetha University, Chennai, India.

${ }^{3}$ School of Dental Sciences, Universiti Sains Malaysia, Health Campus, 16150 Kubang Kerian, Kota Bharu, Kelantan, Malaysia.

${ }^{4}$ Department of Prosthodontics, Faculty of Stomatology, Yerevan State Medical University after Mkhitar Heratsi, Yerevan, Armenia.
\end{abstract}

Correspondence: Anand Marya, Department of Orthodontics, Faculty of Dentistry, University of Puthisastra, Phnom Penh, Cambodia. E-mail: amarya@puthisastra.edu.kh

Academic Editor: Alessandro Leite Cavalcanti

Received: 16 August 2021 / Review: 08 October 2021 / Accepted: 24 October 2021

How to cite: Marya A, Venugopal A, Karobari MI, Heboyan A. Computer vision syndrome: will the pandemic lead to eye
problems for dentists?. Pesqui Bras Odontopediatria Clín Integr. 2022; 22:e210156.
https://doi.org/10.1590/pboci.2022.009

\begin{abstract}
Over the past year and a half dental education has been conducted primarily online due to the SARS-CoV-2 pandemic. During the pandemic, we have spent many hours a day on our computers, mobile phones, and tablets to gather information and participate in online seminars and classrooms. Health consequences resulting from the overuse of these devices include carpal tunnel syndrome as well as computer vision syndrome (CVS). Computer vision syndrome, also known as digital eye strain, has several associated features such as eye burning, strained vision, dry eye, blurred vision, and associated neck and shoulder pain. Several predisposing factors have been linked with CVS, but often this problem gets ignored. The management of this syndrome is aimed at educating dentists on computer use, position, and the surrounding environment. Considering all this, we must ensure that we spend some time away from these devices every day to avoid any significant vision problems. The objective of preparing this manuscript was to provide a brief overview of the increased prevalence of computer vision syndrome and its associated features.
\end{abstract}

Keywords: Vision Disorders; Vision, Low; Microcomputers; Screen Time; Dentists. 


\section{Introduction}

Over the past year and a half dental education has been conducted primarily online due to the SARS$\mathrm{CoV}-2$ pandemic. From university classes to conferences and seminars, every individual in the dental industry has spent much more time online than in the past. While there are many positives associated with virtual or online learning, it is surprising that there has been little mention of the negatives, especially regarding the physical well-being of dental health professionals. During the SARS-CoV-2 pandemic, we have spent many hours a day on our computers, mobile phones, and tablets to gather information and participate in online seminars and classrooms. Health consequences resulting from the overuse of these devices include carpal tunnel syndrome as well as computer vision syndrome (CVS) [1]. Carpal tunnel syndrome is well known and has affected a large segment of the population because of the incorrect position of their hands when using computers [2]. On the other hand, computer vision syndrome causes problems with near vision activities due to the electromagnetic field emitted by various devices' screens [3]. The objective of preparing this manuscript was to provide a brief overview of the increased prevalence of computer vision syndrome, causative factors, and its associated features.

\section{Prevalence}

CVS has a global prevalence of 64 to $90 \%$ among computer users and has affected more than 60 million people globally to date [4]. With an increased online presence during the pandemic, these numbers are only bound to go up worldwide. Estimating the precise prevalence may be a daunting task as there is a variety in the usage of screen-based devices and seating positions. Studies conducted in offices have shown that CVS is more prevalent in women compared to men [5,6]. Previous studies have also demonstrated an increased prevalence of CVS among contact lens wearers [7,8].

\section{Factors}

Internal and environmental factors mainly cause CVS. Internal factors include uncorrected vision or refractive errors, ocular surface disturbances, and binocular vision. Environmental factors include image quality, lighting conditions, display, and seating position, among others [9]. The causative factors for CVS can also be divided into internal/ocular and environmental/non-ocular causative factors [10].

The ocular factors include [11]:

- Pre-existing refractive errors in vision- can lead to neck muscle spasms;

- Reduced rate of blinking of the eye- the standard rate of eye blinking ranges between 20 and 22 times a minute which goes down to 4 to 6 times a minute during screen use;

- Dry eyes- forces screen users to change their head positions, leading to headaches;

- Presbyopia- inability to focus on close objects.

The non-ocular factors include [12]:

- Low screen brightness

- Number of hours of use per day

- Seating position

- Position of the screen.

\section{Features}


The symptoms of CVS vary from one individual to another based on the complex association of the predisposing factors. However, this syndrome has several associated features: eye burning, strained vision, dry eye, blurred vision, and associated neck and shoulder pain [13]. The symptoms have been classified into [14]:

- Ocular symptoms: Eye irritation and burning, excessive tearing, diplopia, blurred vision, light sensitivity, eye fatigue;

- Non-ocular symptoms: Severe neck and shoulder pain, back pain, wrist pain.

\section{Diagnosis}

For establishing a definite diagnosis for CVS, a detailed eye examination is required. First, the patient's history must be recorded along with any relevant medical history. This is followed by an analysis of an individual's refractive errors, presence of eye dryness, visual acuity, general eye health, and presence of binocular vision [15].

\section{Recommendations for Prevention}

Certain recommendations have been given to help lessen the impact of our increased screen time during this period by the College of Dentistry, University of Iowa, some of which are listed below [16]:

- The screen should be placed at a distance of 20 to 28 inches $(50$ to $71 \mathrm{cms}$.) from the eyes and slightly (10 to $12.5 \mathrm{cms}$.) below the eye level (Figure 1). Also, the chair must be positioned to allow the user to sit comfortably.

- The screen should be positioned so that no artificial or natural light falls on it to avoid having to glare.

- Consider using a screen glare filter that lowers the light reflected from the screen.

- An ergonomic chair must be used which has well-designed arm and footrests.

- We must take a break of 15 minutes after every 2 hours of screen use to reduce eyestrain.

- The device brightness, color temperature, and contrast should be adjusted to match those of the surroundings.

- Regular eye examinations every two years from the age of 40 onwards for evaluation of any problems that can be corrected at an early stage [17].

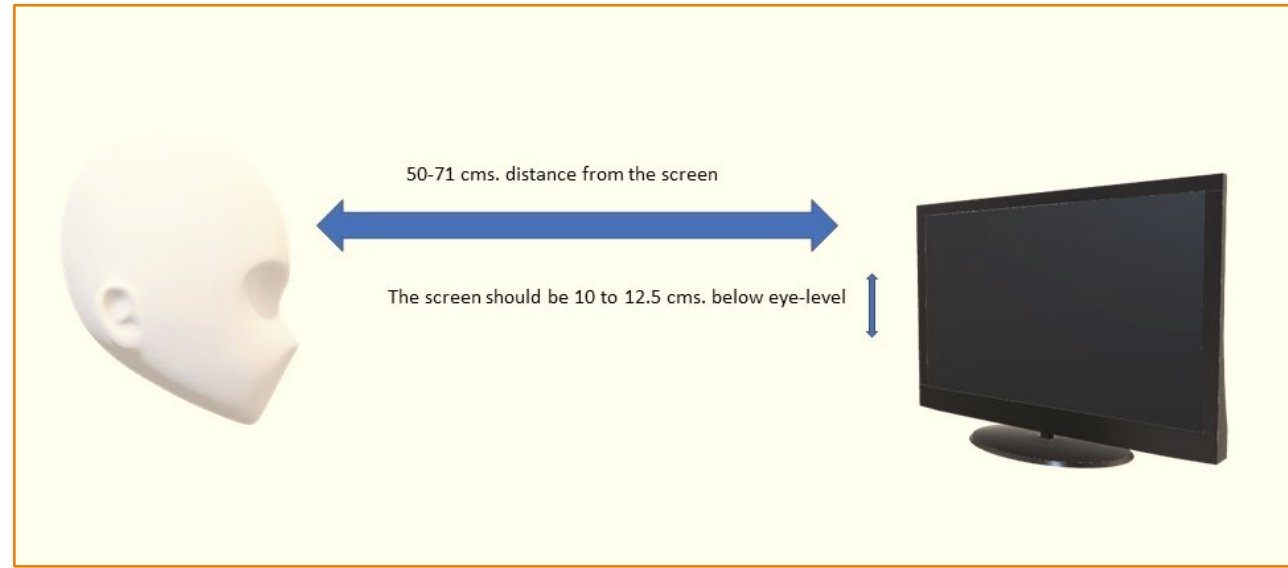

Figure 1. Optimal position of the screen.

\section{Predictions and what can be done}


With webinars and online lectures being conducted every day, there has been a massive rise in the screen time spent by healthcare professionals [18]. Oral healthcare professionals have already been shown in many studies to be at a greater risk of contracting infections compared to other fields [19-21]. Digital eye strain syndrome or computer vision syndrome must be studied in detail regarding its incidence, prevalence, risk categories, and preventive measures to ensure the pandemic does not lead to a "webidemic." Studies must be conducted across all specialties, university, and hospital set-ups to arrive at definite answers in relation to the increasing prevalence of CVS. If this is not controlled in time, the prevalence of this problem is only going to increase, making it a cause of concern.

\section{Conclusion}

Since the onset of the SARS-CoV-2 pandemic, there has been a spurt in the number of webinars globally. There has been a corresponding increase in dentists' inclination to attend such webinars, which has led to dental professionals spending long hours staring at a computer or on mobile screens. This has inevitably predisposed dentists to a higher risk of suffering from symptoms associated with Computer vision syndrome. The treatment of this syndrome is aimed at educating dentists on computer use, position, and the surrounding environment. Considering all this, we must ensure that we spend some time away from these devices every day to avoid any significant vision problems. With such high prevalence, this syndrome is at risk of developing into a global health issue.

\section{Authors' Contributions}

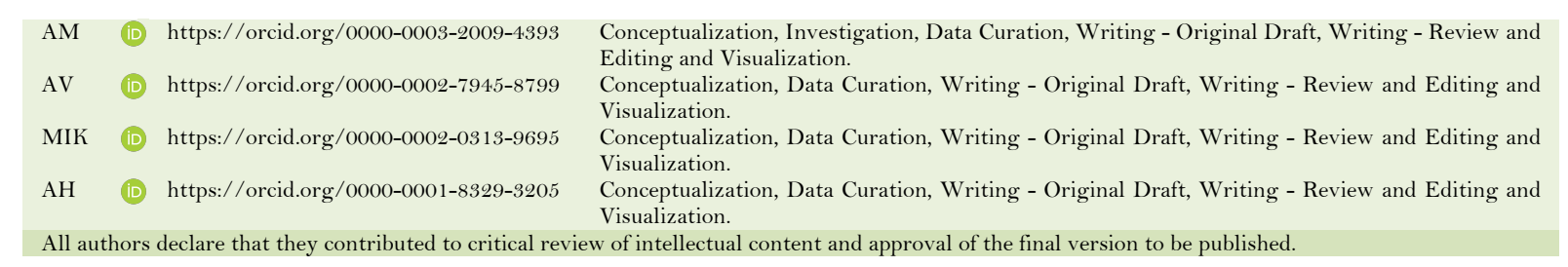

\section{Financial Support}

None.

\section{Conflict of Interest}

The authors declare no conflicts of interest.

\section{Data Availability}

The data used to support the findings of this study can be made available upon request to the corresponding author.

\section{References}

[1] Chu C, Rosenfield M, Portello JK, Benzoni JA, Collier JD. A comparison of symptoms after viewing text on a computer screen and hardcopy. Ophthalmic Physiol Opt 2011; 31(1):29-32. https://doi.org/10.1111/j.1475-1313.2010.00802.x

[2] Rempel DM, Keir PJ, Bach JM. Effect of wrist posture on carpal tunnel pressure while typing. J Orthop Res 2008; 26(9):1269-73. https://doi.org/10.1002/jor.20599

[3] Loh K, Redd S. Understanding and preventing computer vision syndrome. Malays Fam Physician 2008; 3(3):128-30.

[4] Mowatt L, Gordon C, Santosh ABR, Jones T. Computer vision syndrome and ergonomic practices among undergraduate university students. Int J Clin Pract 2018; 72(1). https://doi.org/10.1111/ijcp.13035

[5] Ranasinghe P, Wathurapatha WS, Perera YS, Lamabadusuriya DA, Kulatunga S, Jayawardana N, et al. Computer vision syndrome among computer office workers in a developing country: an evaluation of prevalence and risk factors. BMC Res Notes 2016; 9:150. https://doi.org/10.1186/s13104-016-1962-1 
[6] Klamm J, Tarnow KG. Computer vision syndrome: a review of literature. Medsurg Nurs 2015; 24(2):89-93.

[7] Tauste A, Ronda E, Molina MJ, Seguí M. Effect of contact lens use on Computer Vision Syndrome. Ophthalmic Physiol Opt 2016; 36(2):112-9. https://doi.org/10.1111/opo.12275

[8] Tauste Francés A, Ronda-Pérez E, Seguí Crespo Mdel M. Ocular and visual alterations in computer workers contact lens wearers: scoping review. Rev Esp Salud Publica 2014; 88(2):203-15. https://doi.org/10.4321/S1135-57272014000200004

[9] Blehm C, Vishnu S, Khattak A, Mitra S, Yee RW. Computer vision syndrome: a review. Surv Ophthalmol 2005; 50(3):253-62. https://doi.org/10.1016/j.survophthal.2005.02.008

[10] Kaiti R, Shah P, Bogati B, Shyangbo R, Dahal M, Hamal B. Computer vision syndrome: is it being diagnosed and managed properly?. Acta Sci Ophthalmol 2020; 3(7):13-20.

[11] Hales TR, Sauter SL, Peterson MR, Fine LJ, Putz-Anderson V, Schleifer LR, et al. Musculoskeletal disorders among visual display terminal users in a telecommunications company. Ergonomics 1994; 37(10):1603-21. https://doi.org/10.1080/00140139408964940

[12] Lemma MG, Beyene KG, Tiruneh MA. Computer vision syndrome and associated factors among secretaries working in Ministry Offices in Addis Ababa, Ethiopia. Clin Optom 2020; 12:213-22. https://doi.org/10.2 147/OPTO.S284934

[13] Gowrisankaran S, Sheedy JE. Computer vision syndrome: a review. Work 2015; 52(2):303-14. https://doi.org/10.3233/WOR-152162

[14] Rosenfield M. Computer vision syndrome: a review of ocular causes and potential treatments. Ophthalmic Physiol Opt 2011; 31(5):502-15. https://doi.org/10.1111/j.1475-1313.2011.00834.x

[15] Sheedy JE, Shaw-McMinn PG. Diagnosing and treating computer-related vision problems. Burlington, MA: Butterworth Heinemann; 2003.

[16] Chadwick RG, Alatsaris M, Ranka M. Eye care habits of dentists registered in the United Kingdom. Br Dent J 2007; 203(4):E7. https://doi.org/10.1038/bdj.2007.580

[17] The University of Iowa College of Dentistry. Computer Vision Syndrome (CVS). Available from: https://www.dentistry.uiowa.edu/wellness-computer-vision-syndrome. [Accessed on July 10, 2021 ].

[18] Venugopal A, Jay Bowman S, Marya A. The webinar storm. Br Dent J 2021; $231(6): 316$. https://doi.org/10.1038/s41415-02 1-3484-Z

[19] Marya A, Karobari MI, Selvaraj S, Adil AH, Assiry AA, Rabaan AA, et al. Risk perception of SARS-CoV-2 infection and implementation of various protective measures by dentists across various countries. Int J Environ Res Public Health 202 1; 18(11):5848. https://doi.org/10.3390/ijerph 18115848

[20] Bennett AM, Fulford MR, Walker JT, Bradshaw DJ, Martin MV, Marsh PD. Microbial aerosols in general dental practice. Br Dent J 2000; 189(12):664-7. https://doi.org/10.1038/sj.bdj.4800859

[21] Jain M, Mathur A, Mathur A, Mukhi PU, Ahire M, Pingal C. Qualitative and quantitative analysis of bacterial aerosols in dental clinical settings: risk exposure towards dentist, auxiliary staff, and patients. J Family Med Prim Care 2020; 9(2):1003-8. https://doi.org/10.4103/jfmpc.jfmpc_863_19 